\title{
The Finnish verb repeat response : Its emergence and its nature as a formulaic expression
}

\section{Laury, Ritva}

2018-01

Laury, R 2018 , ' The Finnish verb repeat response : Its emergence and its nature as a

formulaic expression ' , Journal of Pragmatics , vol. 123 , pp. 139-150 . https://doi.org/10.1016/j.pragma.2017.03.003

http://hdl.handle.net/10138/326619

https://doi.org/10.1016/j.pragma.2017.03.003

cc_by_nc_nd

acceptedVersion

Downloaded from Helda, University of Helsinki institutional repository.

This is an electronic reprint of the original article.

This reprint may differ from the original in pagination and typographic detail.

Please cite the original version. 


\section{The Finnish verb repeat response: Its emergence and its nature as a formulaic expression}

\section{Introduction}

This paper concerns the emergence and the status of a standard Finnish response format, the verb repeat, as a unit and as a fixed expression. I examine it here in responses given in ordinary everyday conversation to assessments, informings, and questions. In earlier research, it has been suggested that this response format is the result of ellipsis (e.g. Hakulinen and Sorjonen 2009: 127). I argue that verb repeats do not result from ellipsis, but rather copying, and are manifestations of dialogic resonance (Du Bois 2014), intersubjectivity and the pervasive dialogism of talk-ininteraction (e.g. Linell 2009, Linell \& Mertzlufft 2014, Du Bois 2001, 2014). I also explore the issue of formulaicity of the verb repeat response and suggest that the verb repeat response is a dynamic, emergent unit, and only one of the many formats it may take can be said to approach the status of a fixed expression.

\section{Data and methodology}

The paper is based on data from the Conversation Analysis Archives (Keskusteluntutkimuksen arkisto) housed in the Department of Finnish, Finno-Ugric and Scandinavian Studies at the University of Helsinki. We examined altogether 482 responsive turns in everyday dialogic and multiparty conversations. In all, 135 of responses involved a repeat of the verb in the prior turn. Out of these, 27 responses involved a repetition of only the verb in the prior turn, while another 27 involved the repetition of the verb plus a particle or particles. The 81 responses that included material other than just the verb and possible particles, for example nominal arguments or adverbials, were left outside the study; these responses raise additional issues not relevant to the verb (+ particle) responses, which accept the argument structure of the prior turn as is. In this paper, then, we focus on the 54 minimal verb repeat responses in our data.

The methodology employed in the paper is interactional linguistics, an approach that combines Conversation Analysis with discourse-functional linguistics (Selting \& Couper-Kuhlen 2001). The theoretical perspective central to my analysis is dialogic syntax (Du Bois 2001, 2014), an approach that takes language to be fundamentally dialogic, and structurally built for engagement of the current utterance with prior talk (see also e.g. Bakhtin 1981 [1934], Linell 2009). Dialogic syntax examines how earlier utterances are mapped into current utterances and how such dynamic emergence of structure and its resonance with the structure of prior utterances serves the goals of language users (Du Bois 2014: 360). My approach is also strongly influenced by the closely related theories of emergent grammar (Hopper 1987, 2011) and on-line syntax (Auer 2009); these are approaches which consider the structure of utterances as emerging online, in response to various contextual factors, such as actions of other participants in the conversation, including their prior turns at talk, rather than being determined by pre-existing (a priori) rules. 


\section{The verb repeat as a responsive construction}

In this section of the paper, I will discuss the general features of the Finnish verb repeat response, its various formats, and the contexts in which they are used. What follows is an introduction to the types of verb repeats found in my data, intended as an introduction to the phenomenon for those readers not previously familiar with the Finnish verb repeat response. The formats and their uses will be discussed roughly in the order of frequency in my corpus, with the most common ones first. I will also compare my findings with those of Hakulinen and Sorjonen who have done foundational work on this construction.

The verb repeat response is, of course, a case of repetition. Repetition is used in a range of ways in discourse (see, e.g., Tannen 2007). In Conversation Analysis and interactional linguistics repetition has previously been studied especially in connection with repair (e.g., Robinson \& Kevoe-Feldman 2010, Rossi 2015). In that research, one focus of interest has been prosody (e.g. Benjamin \& Walker 2013). In many uses of repetition, the same speaker produces both instances (for example, in reduplication, which can even be considered, or develop into, a grammaticized instance of repetition; on reduplication, see Lindström 1999). The verb repeat response, of course, differs from most rhetorical uses of repetition, as a defining feature is that another speaker does the repeat.

The use of repetition in answering can be considered a typological feature. In such an approach, languages can be divided into three groups in terms of the response types used (Sadock \& Zwicky 1985; for a summary, see Sorjonen 2001b: 406-407). Some languages, such as English, can be called yes-no languages, where a positive answer is given with a particle like yes, and a negative answer with a particle like no. The second type of languages uses what is called an agree/ disagree system, in which one particle is used for agreeing with the polarity of the prior statement and another one for disagreeing with it; Japanese is a language of this type. A third type of languages uses a so-called echo system, in which the verb of the question is repeated in an answer with or without added material. Taken the phenomenon discussed in this paper, Finnish would then belong to this group. However, Finnish also uses particles to respond to questions, and therefore in fact exhibits a mixed system, as do other languages that have been analyzed as using an echo system, such as Malay, Breton, Welsh, Russian, Czech and Latvian (Jones 1999: 22-36)

In the Finnish verb repeat response, the finite verb in the prior turn is used in the next turn, which then counts as a response to the prior. Consider examples (1), (2), and (3) below. Our first example illustrates a verb repeat in a response to an assessment. In this example, only the copula from the prior assessment is repeated.

Excerpt 1 Onpa hyvää SG 346 Wedding pictures 
(it/this) is good

16

Kerttu: $\quad[(--)$

$17 \rightarrow$ Sanna: on

be.3SG

(yes it) is.

In this excerpt from a multi-party conversation, the participants are eating a broccoli quiche. Eeva first evaluates the quiche positively, using the third person singular present tense form of the copula on 'is' with the emphatic clitic -pA and the partitive form of the adjective hyvä 'good', slightly in overlap with something Kerttu says, but which is not hearable on the recording. Sanna responds to Eeva's evaluation by using the same verb, on, in the same third person singular present tense form as Eeva has just used it ${ }^{1}$. This counts as an agreeing response and essentially the same evaluation: by using the simple verb repeat as a response, its speaker aligns with the prior assessment and asserts "unproblematic and unconditional agreement" with it (Hakulinen \& Sorjonen 2009: 132).

This excerpt is a prime example of the emergence of structure online, in interaction and for interaction (Hopper 2011; Auer 2009). The form of Sanna's response (line 17) to Eeva's assessment (line 15) has everything to do with the fact that it occurs after Eeva's assessment, which is done with the present tense form of the copula, on. The form Sanna uses resonates with Eeva's turn (Du Bois 2014); through the use of the same form, it links the utterances and by doing so, and creates an affinity between them, constituting a response to Eeva's assessment. And, at the same time, Sanna's experience with the Finnish language, the many times that she has heard and used this construction ${ }^{2}$, is what is behind its use; answering this way is a routinized, sedimented grammatical format (Hopper 2011), specifically designed for this kind of context. In this way, the turn expresses Sanna's understanding of Eeva's prior turn as a certain type of action, constructing it as such, and provides an appropriately formatted response (cf. Linell 2009: 229).

The largest number of verb repeat responses in our collection came in responses to assessments (25, out of a total of 54). The most common response to an assessment,

1 In line 19, Sanna repeats only the finite form of the copula, on, not the emphatic clitic -pA used by Eeva in line 15. It is my impression that repeating the clitic would make this utterance more than a response, adding an independent stance.

2 I use the term 'construction' to refer to linguistic entities which link a certain linguistic form or format with a certain meaning and function not entirely predictable from its component parts (Goldberg 2005). 
however, was not a simple verb repeat, as in (1), but rather a verb repeat preceeded by the particle niin, perhaps translatable into English as 'so'. This format was also very frequent in Sorjonen and Hakulinen's data (Sorjonen \& Hakulinen 2009: 283; see also Hakulinen \& Sorjonen 2009: 126). Out of the 25 verb repeat responses to assessments in our data, seven had the form niin on, and there were six additional responses consisting of niin and a different form of the copula olla. In contrast, there were only two uses of simple on as a response. The following excerpt shows a repeat of the copula on preceded by the particle nii(n). The excerpt comes from a conversation among four young women friends.

\section{Excerpt 2 Annun lasit \\ SG151 Girls from Southeastern Finland}

\section{Susa: .hhh nuo on kiva-t nuo Anu-n lasi-t,} DEM .PL be.3SG nice-PL DEM .PL FN-GEN glass-PL

those are nice, those glasses of Anu's/Anu's glasses are nice

(0.4)

\section{$2 \rightarrow$ Jossu: $\uparrow$ nii 0. \\ PTC be.3SG \\ yes they are}

$3 \quad(1.6)$

$\begin{array}{ll}4 \quad \text { Jossu: } & \text { oikein oiva-t, } \\ & \text { very excellent-PL } \\ & \text { really great }\end{array}$

$5 \quad(0.2)$

In excerpt (2), Susa positively evaluates the glasses Anu, another participant, is wearing, and Jossu responds with niin $0^{3}$. According to Sorjonen and Hakulinen, a niin o(n) response to an assessment expresses strong agreement in cases where the object of evaluation is fully shared (2009: 300); it foregrounds the sharedness of the assessment activity. This is the case in excerpt (2): Anu is present in the interaction and wearing the glasses Susa and Jossu are evaluating, so they both have full access to them. Jossu follows her response with an upgraded evaluation, oikein oivat 'really great'.

This excerpt shows that not all verb repeat responses simply repeat the finite verb from the prior turn to which they respond. Other material can also be added, here, the particle niin. This will be important to our argument later on. (See section 4 below on formulaicity of the verb repeat response.)

3 The form 0 , used by Jossu in this excerpt, is a dialectal variant of on. In this paper, I will consider these variants functionally equivalent and not focus on the variation. 
Besides assessments, verb repeat responses are also used in answers to questions. We found 15 verb repeats in responses to interrogatively formatted polar questions formed with the question clitic - $\mathrm{kO}$. The following excerpt is an example of a verb repeat response to a polar question from the same conversation among four young women as Excerpt (2). In this excerpt, the finite verb in the prior utterance is the third person singular form of the Finnish negative auxiliary, ei.

\section{Excerpt 3 Ei onnistu \\ SG151 Girls from Southeastern Finland}

1 Susa: ei-k-s oikei onnistu, NEG.3SG-Q-CLT really work.out.CONNEG It won't really work out, will it

$2 \rightarrow \quad$ Mila: e:i.

NEG.3SG

no, it won't

Just prior to this exchange, Anu has suggested going out together the same evening. Miia has been equivocating (not shown). Susa then asks Miia a negatively formatted question, using the negative auxiliary with the question clitic - $\mathrm{kO}$, here reduced to $\mathrm{k}$-, followed by another clitic, -s, and Miia responds by repeating the third person singular form of the negative auxiliary. The Finnish negative auxiliary carries person marking and is thus the finite verb in the clause, and in a response to negatively formatted utterances, this is what gets repeated (cf. Hakulinen \& Sorjonen 2013). By repeating the negative auxiliary, Miia agrees that the plans won't work out.

Verb repeats were also used nine times in response to informings in our data. The next example comes from a conversation between two sisters. They have been discussing using honey in cooking.

\section{Excerpt 4 Siirappia \\ SG 437 Sisarukset}

69 Tuula: kerran mä te-i-n, (0.6) ((licking fingers))

once 1SG make-PST-1SG (0.6)

once I was making, (0.6)

70

hmm, (1.0)

hmm, (1.0)

71

mt 个kaali-pata-a. (0.6) ja, (0.2) ((licking fingers))

cabbage-casserole-PAR and

$\mathrm{mt}$ cabbage casserole. (0.6) and (0.2)

72

ms sii-he-hän tule-e

DEM-ILL-CLI come-3SG 
ms y'know you know you put

73

siira- siirapp[i-a,

mola- molasses-PAR

molasses in it

$74 \rightarrow$ Jaana:

[niin tule-e;

PTC come-3SG

[yes you do

75

(.)

In lines 69-73, Tuula starts a narrative about cooking a cabbage casserole. In lines $72-73$, she mentions the fact that cabbage casserole is supposed to have molasses in it. In line 72, in the initial element of the clause that contains this informing, she uses the clitic-hAn, which expresses that the information expressed in the clause that follows is shared. In response to this, Jaana repeats the main verb in Tuula's clause, tulee, preceded by the particle niin. As suggested by Hakulinen and Sorjonen (2013), this format, in which the particle niin is followed by the verb repeat, asserts unmodified agreement. In addition, it also expresses the speaker's independent access to the matter under discussion. In other words, in Excerpt 4, in addition to agreeing with Tuula about what goes into a cabbage casserole, Jaana also asserts her own epistemic access to the recipe.

We also found three uses of verb repeat responses to particle questions, involving responses to receipts to informings containing the news receipt particle ai (Hakulinen et al. 2004: §) and questions done with the particle vai (Koivisto to appear), as well as two uses in responses to requests. We did not find verb repeats in responses to any other types of actions in our data.

\begin{tabular}{|l|l|l|l|}
\hline $\begin{array}{l}\text { Function of prior turn/ Response } \\
\text { format }\end{array}$ & $\begin{array}{l}\text { Verb repeat } \\
\text { only }\end{array}$ & $\begin{array}{l}\text { Verb + } \\
\text { particle(s) }\end{array}$ & Total \\
\hline Informing & 2 & 7 & 9 \\
\hline Assessment & 8 & 17 & 25 \\
\hline Polar question done with -kO & 13 & 2 & 15 \\
\hline Particle question & 3 & 0 & 3 \\
\hline Request & 1 & 1 & 2 \\
\hline Total & 27 & 27 & 54 \\
\hline
\end{tabular}

\section{Table 1. Number of verb repeat responses by function of prior turn and response format}

Table 1 shows that there were equal numbers of verb repeat responses in our data which contained only the finite verb from the prior turn and ones that involved the use of a particle or particles as well. There were 27 of each type. In our data, the verb repeats responded most commonly to assessments ( 25 cases); 15 of the prior turns were polar questions done with the clitic - $\mathrm{kO}$; particle questions were much 
less common, only three in number ${ }^{4}$. In nine cases in our data, the verb repeat came in response to an informing, and two requests in our data received a verb repeat response. Assessments and polar questions appear to prefer different formats of verb repeat responses; the verb repeat responses to assessments in our data were approximately twice as likely to be done with verb and particle or particles rather than a bare verb (17/8)), while verb repeat responses to questions were eight times more likely to be done just with a verb (16/2). The three particle questions each received simple verb repeats as responses. However, since our sample is rather small, it is not possible to draw firm conclusions from these skewings in the data, especially when it comes to particle questions and requests.

The Finnish verb repeat response has been studied extensively in a series of papers by Sorjonen and Hakulinen, as has already become apparent. They have studied particular variants of this expression in responses to questions (Sorjonen 2001a, b; Hakulinen 2001), assessments (Hakulinen \& Sorjonen 2009, Sorjonen \& Hakulinen 2009), and negative stancetakings (Hakulinen \& Sorjonen 2014).

Relevantly to the paper at hand, Sorjonen (2001b) and Hakulinen (2001) deal with simple verb repeats; Hakulinen (2001) also discusses verb repeats with particles. Citing earlier work by Raevaara (1993) and Sorjonen (2001a), they show that simple verb repeats are used to respond to questions that are information-seeking and interrogatively formatted, and provide an affirmative answer to the question, offering new information which then becomes intersubjectively shared (Sorjonen 2001b: 411). They also suggest that the activity in which the question is located "typically needs to be continued after the verb repeat answer" (Hakulinen 2001: 3; see also Sorjonen 2001b: 411).

In two co-authored papers (Hakulinen \& Sorjonen 2009, Sorjonen \& Hakulinen 2009) Hakulinen and Sorjonen examine verb repeat responses to Finnish assessments done with a copula and an assessment term. While they acknowledge that a range of verbs is used in assessments, and thus also in agreeing verb repeats, they focus here on repeats of on, the third person singular present tense form of the verb olla 'to be', used as a copula in the preceding predicate nominal clause expressing an assessment. They show that while the repeat of just the verb simply asserts agreement with the preceding assessment, as already shown in their earlier papers, the inclusion of the subject and variation in the order of subject and verb make epistemic claims, expressing differences in perspective and experience between the participants. On the other hand, the addition of the particle joo implies topic closure, something this particle has been noted to do in other activity types as well (e.g. Sorjonen 2001a), and as was already suggested by Sorjonen (2001b) Hakulinen (2001). In Sorjonen and Hakulinen (2009), it is also shown that the verb repeat done with the particle niin expresses that the assessment activity is a shared

\footnotetext{
4 Particle questions are a syntactic question type in Finnish (Hakulinen et al. 2004 §1679) formed with a particle, either vai 'or' (Koivisto forthcoming) or entä(s) 'and what about', instead of the clitic - $\mathrm{kO}$, or an interrogative pronoun.
} 
one. While this response asserts agreement, it may also precede the expression of its speaker's opposite stance.

In a later paper, Hakulinen and Sorjonen (2011) focus on responses to negatively formatted stance expressions done with ei, the Finnish negative auxiliary. In this paper, reminiscent of the papers on variations of on-responses, they argue that while the repeat of ei by itself expresses an unmodified and unconditional agreement with the earlier utterance, the addition of the particle niin is used to encode independent epistemic access its speaker has to the matter expressed in the prior utterance. My data also include responses that repeat the negative verb from the prior turn. These include assessments, and they seem to function in ways similar to those found by Hakulinen and Sorjonen in their data. Excerpt 3 above is an example of responding with ei in to a question; Susa's negatively formatted polar question implies that going out won't work out, and Miia's response confirms that.

The findings of Hakulinen and Sorjonen for the verb repeat response types they studied hold for my data also. They are used in responses to assessments, as well as questions and informings. In what follows, I will focus on the emergence of the verb repeat response, its status as a fixed expression, and its unit status. I will suggest that, differently from what has been suggested in earlier research, verb repeat responses do not emerge in conversation through ellipsis, but rather through copying. For one thing, in responses, minimal forms are more basic than longer forms, and thus are best not considered derived. Further, I will show that the ellipsis explanation is inadequate to explain cases where the verb repeat is not a direct repetition of the verb in the prior turn. Instead, I will suggest that the verb repeat response is a manifestation of the pervasiveness of dialogicality in interaction, the engagement of current utterances with prior text.

\section{How do verb repeat responses emerge in conversation?}

As shown in examples (1-4) above, as well as in prior research quoted in the previous section, in a verb repeat response, the finite verb from the prior turn is repeated. This happens in responses to assessments (1 and 2), answers to interrogatively formatted questions (3), and in responses to informings (4). As noted, repeating the verb form from the prior turn affirms the state of affairs questioned in, or asserts agreement with that prior turn, while the addition of particles adds further sequential and/ or epistemic or other stance related implications. Further, the repetition of only the verb, possibly with a particle or particles, marks the turn as a response to the prior, leaving the rest of the prior turn to stand, thus marking it as intersubjectively shared (Sorjonen 2001a: 39; Hakulinen and Sorjonen 2009:127)5.

\footnotetext{
${ }^{5}$ One might assume that everything that is said in conversation automatically becomes intersubjectively shared; this is also something suggested by one of the anonymous reviewers. However, there is some reason to assume that this is not so. Although your interactant says something, you may not be attending, or you may not share an assessment
} 
But what is the mechanism involved in the verb repeat? Hakulinen and Sorjonen have suggested that the verb repeat response involves ellipsis. For example, for verb repeat responses to assessments, they suggest that "(t)hrough ellipsis, the speaker leaves both the subject and the assessment term of the prior turn intact. For that reason the response type is maximally built as a second action and thereby indexes alignment with the prior assessment" (2009: 127; see also 2013: 235; Sorjonen \& Hakulinen 2009: 238).

Ellipsis is a topic addressed by linguists working in both functional and formal paradigms. The central idea for the concept is that nonsentential elements ("fragments") emerge when a clausal utterance is first generated, and then parts of it are "deleted" or "elided" or "not pronounced" (Goldberg 2005: 11) resulting in overt structure which is not a full clause (or "sentence"). As early as the 1920s, linguists have criticized what they considered the overreliance of linguists on ellipsis as an explanation, noting that nonsentential entities, often called "fragments", can be interpreted directly (Jespersen 1924: 306; Bühler 1934: 155). In formal linguistics, several different types of ellipsis have been identified, but it remains controversial whether "fragmentary" utterances such as short answers and other subsentential utterances have fully sentential syntactic structures, subject to ellipsis. While some formally oriented contemporary linguists have argued that such structures can be interpreted directly (e.g. Jackendoff 2002), others (see, for example, Newmeyer 2003; Merchant 2004) argue for ellipsis.

However, ellipsis is not an entirely satisfactory explanation for verb repeat responses. One reason for this is simply that syntactically minimal utterances are preferred or default in responsive turns (Raymond 2000, 2003) and thus, as suggested by Hopper (2001: 36), the more basic form, while the fuller form has additional pragmatic functions. Along the same lines, Thompson, Fox \& CouperKuhlen suggest that, for English, "syntactically minimal forms are the most frequent and no-problem response type", at least in many environments, and, importantly for our purposes here, they suggest that ellipsis is not a useful description for them, since they do specific work in their contexts of use, and are therefore not usefully described as lesser, derived versions of the utterances they respond to (2015: 7; 300-302). As already proposed by Selting (1997), the minimal utterances in second pair parts of adjacency pairs are in fact sequentially conditioned and constrained; they occur in certain kinds of positions (responses) in certain kinds of sequences (e.g., in question-answer or assessment sequences). Thus they are strongly dependent on co-text; put another way, they are "positionally sensitive (Schegloff 1996)". In fact, the minimal utterances examined here, verb repeat responses, reflexively build the sequences in which they occur into certain types.

that is made; what is said may be disagreed with or repaired by another participant. We do not in fact know what is actually shared from prior text until it is made visible somehow. A verb repeat, therefore, can be said to be marking what it responds to as shared, as suggested by Sorjonen and Hakulinen (2009). 
A further complication is that in many cases, the verb repeat is not a direct repetition of the finite verb in the prior turn, so that further operations besides copying and ellipsis would be required (see also Thompson, Fox and Couper-Kuhlen 2015: 299-301 for a similar argument based on English data). For one thing, there may be a difference in tense, polarity or person between the finite verb in the prior turn and the response. Other material may also be added. Consider excerpt (5), which comes from the same conversation as excerpt (4). It shows a case where a verb repeat response to an assessment is in a different tense and has different polarity than the verb in the assessment, and involves the addition of two clitics and a final particle.

\section{Excerpt 5 Hyvä idea \\ SG 437 Sisarukset}

\begin{tabular}{|c|c|c|c|}
\hline 158 & Jaana: & $\begin{array}{l}\text { tää ol-i } \\
\text { DEM be-PST.3 } \\
\text { this was a good }\end{array}$ & $\begin{array}{l}\text { muuten hyvä idea } \\
\text { SG PTC good idea } \\
\text { dea by the way }\end{array}$ \\
\hline 159 & & $\begin{array}{l}\text { tä-tä mä } \\
\text { DEM-PAR 1SG } \\
\text { this I'll start }\end{array}$ & $\begin{array}{l}\text { muuten rupee-n, } \\
\text { PTC start-1SG }\end{array}$ \\
\hline $60 \rightarrow$ & Tuula: & $\begin{array}{c}\text {.mt [ei-kö } \\
\text { NEG.3SG-Q } \\
\text { mt isn't it yeah }\end{array}$ & $\begin{array}{l}\text { 个o]lek-kin joo. } \\
\text { be.CONNEG-CLI PTC }\end{array}$ \\
\hline
\end{tabular}

161 Jaana: $\begin{gathered}\text { [nyt viljele-e,] } \\ \text { now cultivate-INF } \\ \text { [now using }\end{gathered}$

At this point in the conversation, Tuula and Jaana are drinking coffee fortified with liquor. Jaana, the guest, assesses the adding of liquor to the coffee as a good idea in line 158, using a past tense form of the copula, oli. Tuula, the host, responds in line 160 with an agreeing verb repeat, formatted as a question in the negative form. In her response, the negative auxiliary with the question clitic -kö is combined with the connegative form of the copula used by Jaana in her turn. This is a present tense format (the negative auxiliary does not carry tense, but for past tense, it is combined with a participle, yielding a past interpretation). The clitic - kin has been added to the connegative form of the copula. What we have here is a common format for responding to a compliment in Finnish, expressing that the responding speaker agrees and has also already independently come to the same conclusion (Etelämäki, Haakana \& Halonen 2013: 477; see also Hakulinen et al. 2004: §843 on -kin) ${ }^{6}$. This verb repeat is then followed by the particle joo, also common in responses to Finnish compliments. According to Sorjonen (2001a: 199), joo as a response to a

\footnotetext{
${ }^{6}$ As Etelämäki et al. note, a similar construction has also been found in responses to compliments in other languages.
} 
compliment treats the preceding turn as an informing rather than as a compliment, thus avoiding self-praise.

Ellipsis does not work well as a mechanism for a verb repeat such as the one in excerpt (5). It is of course possible that the recipient would first create a matching utterance, ellipt all the material besides the verb, add a negative auxiliary with the question clitic, reformat the verb into a connegative form, add the -kin 'also' and the response particle joo. However, this would be a complex operation ${ }^{7}$.

Simple verb-only repeat responses can also be problematic for ellipsis. Consider the following example, from the same conversation as excerpt (3).

\section{Excerpt 6 Salilla \\ SG151 Girls from Southeastern Finland}

834 Susa: nii oo-t sie jo tänä aamuna ollu jo salilla, PTC be-2SG 2SG already DEM -ESS morning-ESS be-PCP already gym-ADE So have you already this morning already been to the gym

$835 \rightarrow$ Anu: $\quad$ o(h)on.

be-1SG

yes I have

In this excerpt, Susa asks Anu whether she has already been to the gym that same morning 8 , and Anu responds with a verb repeat. However, the auxiliary (the finite, person marked part oot of the present perfect construction oot ollu '(you) have been') is in the second person form, and Anu's response is in the first person form. If the response were to have been arrived at through ellipsis, Anu presumably would first have to copy Susa's utterance, then construct a modified form of the utterance in the first person, and then ellipt all but the auxiliary. On the other hand, if Anu would simply copy Susa's utterance as is, ellipt all the other material from the question as it stands, besides the finite verb, she would still have to modify the verb form to give an appropriate answer.

A different way to consider responses which repeat parts of a previous turn and depend on its content for understanding is what Auer (2014) calls analepsis. In analepsis, the responding turn would be "taken from" a prior turn, rather than something being "ellipted" or taken away from a responding turn. Through analepsis, "grammatical structure already established remains available" through

\footnotetext{
${ }^{7}$ It is of course possible that this response format is formulaic, and thus emerges as a readybuilt whole. We will return to this issue in the next section of the paper.

8 Susa's question lacks the question particle -ko; this is a feature of the dialect used in this conversation. The VS word order can be construed as marking this utterance as a question (Hakulinen et al. 2004, §1689), although such a word order is possible in plain statements as well. In any case, Anu's response treats Susa's utterance as a question, as discussed below.
} 
"structural latency" involving "the continuing activation of a syntactic pattern" from an earlier utterance (Auer 2014: 533). This approach explains better what happens with verb repeat responses than the ellipsis explanation does, since what seems to be happening is that the earlier utterance does seem to remain available, in fact it is crucial, for the interpretation of the response. However, in the case of verb repeat response, it is not primarily, or at least not only, the syntactic structure of the prior utterance that is borrowed or activated, but also its semantics and pragmatics.

Regarding the nature of the 'symbionts', the utterances that are analeptically related to an earlier utterance, Auer goes on to say that "linguistic symbionts do not have a structure at all without their host. They borrow their structure from it, and only replace some of its elements to become separate units bringing additional meaning into the conversation (Auer 2014: 535)." This understanding of analepsis does not fit the verb repeat responses very well, because they can and do have a structure of their own. In fact, the format of the verb repeat response is what is crucial for its function as a response; in Hakulinen and Sorjonen's words, it is "maximally built as a second action (2009: 127)". What is crucial for the verb repeat response to do its work in interaction is precisely its format, in addition to the fact that it repeats the finite verb from the prior turn. Even beyond the verb repeat, as we have seen, verb repeat responses also have their own structure, crucial for the interpretation of the action they accomplish in their sequential slot: for example, the particle before the verb repeat in (4), the negation and clitics in (5), and the person marker in (6) are all meaningful for the interaction at hand.

What appears to be central in the emergence of the verb repeat response is the relatedness on the level of sequence and action of the prior turn and the response to it. Imo (2014) proposes a novel understanding of ellipsis and suggests that ellipses "be treated as structures in their own right, not as deficient patterns where some parts have to be 'filled in' to create the utterance that the speaker might have intended. Nevertheless, while the parts that are 'missing' do not transform the ellipsis into an ungrammatical or deficient structure, they still play a role in the dialogical situation between the producers and recipients of an utterance (142)." I completely agree with Imo regarding the nature of structures often thought to have resulted from ellipsis as structures on their own right, and not as deficient patterns. However, it does not seem useful to me to extend the meaning of ellipsis in this fashion, when the phenomenon can be explained through dialogicality and resonance, as I suggest next. In such an approach, the role of the parts of the prior utterance not repeated in the response is still taken into account, without using the term 'ellipsis', as done by Imo.

What seems to be involved in verb repeat responses, rather than ellipsis, is precisely dialogicality (e.g. Du Bois 2001, 2014; Linell \& Mertzlufft 2014; other papers in Günthner, Imo \& Bücker 2014). Dialogicality involves an engagement of current utterances with prior text, words that have been spoken before (Bakhtin 1981 [1934]; Becker 1995; Linell 2009; Voloshinov 1973 [1929]). In Du Bois' terms, the verb repeat response resonates with what has been said just prior. More than 
copying, what is involved here is partial matching between two utterances and the meaning and action created through that matching. Beyond that, both parts are needed; the formatting of both and their resonance is what creates the sequential and actional meaning and the intersubjective understanding in the context of interaction. What makes dialogic syntax a particularly suitable framework for the description of verb repeat responses is that unlike ellipsis, it allows for partial matching, the selective invocation of linguistic resources put to use by another speaker; the second speaker's meaning can then be "parallel, opposed or even orthogonal to that of the first" (DuBois 2014: 361). It is this juxtaposition of utterances, or "structural coupling", engagement of one utterance with another, that creates the meaning. To illustrate, consider excerpt (6), repeated below.

\section{Excerpt 6 Salilla (repeated) \\ SG151 Girls from Southeastern Finland}

\section{Susa: nii oot sie jo tänä aamuna ollu jo salilla, PTC be-2SG 2SG already DEM -ESS morning-ESS be-PCP already gym-ADE So have you already this morning already been to the gym}

\section{Anu: o(h)on. \\ be-1SG \\ yes I have}

Although Susa's utterance in line 834 lacks a question particle, it is reflexively acknowledged as a question by Anu's turn in line 835, which is formatted as an answer by repeating the finite part of the verb complex, the auxiliary, and in this case, only the auxiliary, from Susa's turn in line 835. The repetition of the auxiliary creates resonance between the two utterances: Anu's turn is dialogically related to Susa's utterance and responds to its content, affirming it. More than that, the use of the first person form in the repeat of the copula, oon indexes Anu's role as the addressee of Susa's question in line 834, and as the referent of sie 'you-SG' in Susa's utterance.

Dialogic syntax works as an approach to explaining verb repeat responses because it does not require exact reproduction of the prior, as in ellipsis, but only partial matching. Therefore, we can consider all the examples in this paper as instances of dialogicality; it is the copying of the verb from the prior utterance that marks the utterance as a response to the prior. The repeat of only the verb from the prior utterance, as in (1), simply responds to and accepts the prior. Further shaping of the utterance through deictic shifts as in (6) above, or through the addition of particles, create additional meaning. In (2) and (4), the resonance created through repetition of the verb makes the turn into an agreeing response; the addition of the particle niin expresses a certain kind of epistemic stance. In excerpt (3), the answer to the question takes the form of a negative verb, but creates an agreeing response nevertheless, since the question that the verb repeat responds to was negatively formatted. And in excerpt (5), the resonance created by the repetition of the verb again makes the response an agreeing one, but the rest of the formatting analyses 
the action of the prior turn as a compliment; the format is a conventionalized way of responding to a compliment. Thus the response is resonant and dialogic both on the morphosyntactic level as well as on the level of action.

In this section of the paper, I have argued that the verb repeat response is best accounted for by dialogic resonance, rather than ellipsis or analepsis. In the next section, I will briefly discuss the status of the verb repeat response as a fixed expression.

\section{Verb repeat responses as formulaic expressions}

Are Finnish verb repeat responses formulaic - are they perhaps even fixed expressions $^{9}$ ? Formulaic language is characterized by both restricted form and restricted distribution; formulaic expressions are, by definition, "not amenable to lexical and structural reformulation" and "tend to occur in particular styles of language tied to particular communicative situations" (Corrigan et al. 2009: xiv). On the whole, the role of formulas in language has perhaps been underestimated; Erman \& Warren (2000) found that formulas account for 55\% of language use. For that reason alone, they are worth investigating. The reverse is also true: formulaic expressions are frequently used. Wray suggests that frequency of use is "probably an agent of formulaicity" (2013: 316; see also Bybee \& Cacoullos 2009).

The verb repeat responses are formulaic in terms of their distribution: they occur in conversational language, and in a particular communicative situations, in responses to certain kinds of actions. The form of the verb repeat response is to a certain degree restricted and in that sense also formulaic: it involves the repeat of the finite verb in the prior utterance, to which it responds. However, what is the degree of fixedness? Can it be described as a fixed expression? Something like that is perhaps alluded to by Hakulinen and Sorjonen in their most recent series of papers on the topic, where they refer to the forms they study as "the paradigm of utterance types (2009: 124)" used in response to assessments and "the range of variants used when an agreement is given by repeating the finite verb of the participant's prior utterance (2009: 125)." To be sure, Hakulinen and Sorjonen carefully note that they have focused on responses to certain types of assessments done with the copula on 'is', and thus responses done with on, and that other verbs can also occur in assessments and responses to them, but that they were rare in their corpus of 52 cases.

\begin{tabular}{|l|l|l|}
\hline $\begin{array}{l}\text { niin on } \\
\text { PTC be.3SG }\end{array}$ & $\begin{array}{l}\text { on } \\
\text { be.3SG }\end{array}$ & $\begin{array}{l}\text { on joo } \\
\text { be.3SG PTC }\end{array}$ \\
\hline $\begin{array}{l}\text { on se } \\
\text { be.3SG DEM }\end{array}$ & $\begin{array}{l}\text { on on } \\
\text { be.3SG be.3SG }\end{array}$ & se on \\
DEM be.3SG \\
\hline
\end{tabular}

${ }^{9}$ I take formulaicity to be a continuum, while fixed expressions are an extreme case of formulaicity. 


\section{Table 2. The paradigm of utterance types used in response to assessments done with the copula on(Hakulinen and Sorjonen 2009)}

As in Hakulinen and Sorjonen's data, also in our data the response format niin on is the most common format in responses to assessments. It is also used in response to informings in our data. Out of all the 54 responses in our data, niin on occurred seven times. In addition, niin occurred six more times with other forms of olla 'to be', such as in the past tense; it can also be found in person forms other than the third person singular on ${ }^{10}$. Likewise, the order of the particle niin and the repeated verb olla was constant in our data, so that niin always preceded the copula, as in excerpts (2) and (4). This is not the case with the particle joo, which could either precede or follow the verb repeat, as in exerpt (5). However, of the formats studied by Hakulinen and Sorjonen (2009), the response on joo did not occur in our data, and we did not consider responses including the subject, so we have little to say about the formats se on and on se, 'it is'. We also did not find any uses of reduplication of on, although there was one case of a response where on was repeated three times. Thus, not all of these responses are very common, and therefore possibly not formulaic.

Altogether, there were 19 verb repeats in our data where the particle niin was one of the other elements. It also occurs with other verbs besides on. For an example of the use of niin with a verb other than olla, see excerpt (4) above, involving niin with tulla 'come'. There were four uses of niin with verbs other than olla in our data, including two uses with tulla. The particle niin also occured twice in verb repeats involving the negative auxiliary ei, but in such verb repeat responses, niin comes after ei, as in the example below.

\section{Excerpt 7 Lipsahdus \\ SG 441 Family dinner}

1 Liisa: ei-hän si-tä pys[ty sit (.) enää *u se NEG-CLT DEM -PAR be.able-CONNEG then any.longer when DEM

You can't any longer then when the

2 Virpi: $\quad\left[{ }^{\circ} \mathrm{mm},{ }^{\circ}\right.$

3 Liisa: virhe on ta[pahtu-nu<ni ei-hän si-tä pysty mistake be.3SG happen-PCP so NEG-CLT DEM-PAR be.able-CONNEG mistake has happened so it can't
$4 \quad$ Virpi:
$\left[^{\circ} \mathrm{ei} \mathrm{nii}^{\circ}\right.$
NEG PTC
That's right

\footnotetext{
${ }^{10}$ I thank Marja-Liisa Helasvuo for providing me an example in which this format occurs with olla in a second person singular form.
} 


\section{Liisa: enää korjaa-maa [se-n jälkeen. \\ any.longer correct-INF DEM-GEN after \\ be corrected any longer after that.}

This excerpt relates to a discussion about misbehavior at school. Liisa suggests that once one has misbehaved, it cannot be corrected. Virpi's agreeing response, a repeat of the negative auxiliary, is in line (4). Hakulinen and Sorjonen (2011) suggest that ei niin responses express that their speaker has independently come to the same conclusion as the speaker of the prior turn. The fact that the response comes in overlap at a point where Virpi has not come to a transition relevance point in her turn (the main verb, korjaamaa 'correct-INF' in line 5 has not come yet, and the utterance is prosodically incomplete as well) also indicates that Virpi considers herself to have independent epistemic rights to the matter (Vatanen 2014).

Since there were as many as twelve verbs other than olla involved in verb repeat responses in our data, including two auxiliaries, ei and voida 'to be able to', it is not possible, at least on the basis of our small collection, to say that any of the verb repeat responses have the status of the formula or fixed expression, with the possible exception of niin on. Given the variation in tense and person and the possible addition of other particles even with uses of olla, such as for example in the response joo niin oli, involving the use of the two particles joo and niin with a past tense form of olla, there is little reason to say that even the formats using olla are highly formulaic or constitute a paradigm of uses. However, they are fixed expressions in the sense that they always, in their use as responses, involve the repeat of the finite verb from the prior turn.

Instead, the verb repeat response is a construction with considerable variation, with one constant, involving the repeat of the finite verb from the prior utterance, and a constant meaning, that of indexing the turn it contains as a response to that prior turn. They emerge dynamically as responses, creating dialogic resonance by repeating a particular element of the prior turn, with meaningful variation expressing a variety of epistemic stances and analyzing the prior turn in a variety of ways. In that sense, verb repeat responses can also be said to be independent, somewhat fixed units on their own.

\section{Conclusion}

In this paper, I have shown that Finnish verb repeats occur as responses to a variety of actions. I have also suggested that the Finnish verb repeat response is not an elliptical expression, but that it can be best described as involving dialogic resonance with a prior turn to which it responds. While the verb repeat response format does manifest formulaicity, as it always involves the copying of the finite verb from the prior utterance to which it responds, verb repeat responses involve a variety of verbs, and, based on the data examined here, only one of the response formats, niin on, can be characterized as a fixed expression . 
Verb repeat responses are also manifestations of the intersubjectivity of interaction, as they mark the prior to which they respond as intersubjectively shared. Their form and its resonance with what precedes indexes them as involving a certain kind of action, a response, relating to the prior action to which they respond. The verb repeat responses are specifically fitted for use in responding, and construct the actions that occur before them, assessments, questions and informings, as actions which invite response. The verb repeat response is a linguistic element that illustrates the deeply entrenched dialogicality and formulaicity of human language and the emergence of structure online in interaction.

\section{Acknowledgments}

I gratefully acknowledge the support of the Academy of Finland for the project "The Question of Units in Grammar and Interaction" and the help of the research assistants Karita Suomalainen and Päivi Hakamäki in the organization and analysis of the data. I am grateful for the comments from the participants in the Units in Responsive Position symposium organized in Turku in March 2015, and in the Midpoint Seminar of the Finnish Center of Excellence for the Study of Intersubjectivity in Interaction held in Helsinki, also in March 2015. I am also grateful for the comments of Marja-Liisa Helasvuo and Tomoko Endo as guest editors of this special issue, and for the helpful comments of the two anonymous referees, which have forced me to sharpen the analysis and enrich its background.

\section{References}

Auer, Peter, 2009. On-line syntax: thoughts on the temporality of spoken language. Language Sciences 31 1-13.

Auer, Peter, 2014. Syntactic structures and their symbiotic guests. Notes on analepsis from the perspective of on-line syntax. Pragmatics 24 (3): 533-506 Bakhtin, Mikhail M, 1981 [1934] The dialogic imagination: Four essays by M. M. Bakhtin. Austin, TX: University of Texas Press.

Becker, Alton L., 1995. Beyond translation: Essays toward a modern philology. Ann Arbor, MI: University of Michigan Press.

Bühler, Karl, 1934. Sprachtheorie. Die Darstellungsfunktion der Sprache.Jena:

Fischer.

Bybee, Joan \& Rena Torres Cacoullos, 2009. The role of prefabs in grammaticization. How the particular and the general interact in language change. In: Roberta Corrigan, Edith A. Moravcsik, Hamid Ouali \& KathleenWheatley (eds), Formulaic Language, Amsterdam: Benjamins. 187-217.

Corrigan, Roberta, Edith A. Moravcsik, Hamid Ouali \& Kathleen Wheatley, 2009. Introduction. Approaches to the study of formulae. In: Roberta Corrigan, Edith A. Moravcsik, Hamid Ouali \& KathleenWheatley (eds), Formulaic Language, Amsterdam: Benjamins.

Couper-Kuhlen, Elizabeth, Barbara Fox and Sandra A. Thompson, 2014. Forms of dialogism: Grammatical formats for responsive actions. In: Susanne Günthner, Wolfgang Imo \& Jörg Bücker (eds), Grammar and dialogism. Berlin: Mouton. 109130. 
Du Bois, John W., 2001. Towards a dialogic syntax. Ms., University of California, Santa Barbara

Du Bois, John W., 2014. Towards a dialogic syntax. Cognitive Linguistics 25 (3) 359410.

Etelämäki, Marja, Markku Haakana \& Mia Halonen, 2014. Keskustelukumppanin kehuminen suomalaisessa keskustelussa. [Compliments in everyday Finnish conversation.] Virittäjä 117: 4. 460-493.

Erman, Britt and Beatrice Warren, 2000. The idiom principle and the open choice principle. Text 20 (1): 29-62.

Günthner, Susanne, Wolfgang Imo \& Christine Mertzlufft (Eds), 2014. Grammar and Dialogism : Sequential, Syntactic, and Prosodic Patterns between Emergence and Sedimentation. Hawthorne, NY: De Gruyter.

Hakulinen, Auli, Maria Vilkuna, Riitta Korhonen, Vesa Koivisto, Tarja Riitta Heinonen \& Irja Alho, 2004. Iso suomen kielioppi. [The Comprehensive Grammar of Finnish.] Helsinki: Suomalaisen Kirjallisuuden Seura.

Hakulinen, Auli \& Marja-Leena Sorjonen, 2009. Designing utterances for action:

Verb repeat answers to assessments. In: Markku Haakana, Minna Laakso \& Jan Lindström (Eds), Talk in Interaction: Comparative Dimensions.. Helsinki:

Suomalaisen Kirjallisuuden Seura. Studia Fennica Linguistica 14. 282-302. Hakulinen, Auli \& Marja-Leena Sorjonen, 2011. Ways of agreeing with negative stancetaking. In: Tanya Stivers, Lorenza Mondada \& Jakob Steensig (Eds) The Morality of Knowledge in Conversation. Cambridge: Cambridge University Press. Hopper, Paul, 1987. Emergent Grammar. In: Proceedings of the Thirteenth Annual Meeting of the Berkeley Linguistics Society. 139-157.

Hopper, Paul, 2011. Emergent grammar and temporality in interactional linguistics.

In: Peter Auer \& Stefan Pfänder (Eds) Constructions: Emergent and Emerging. Berlin: Mouton de Gruyter. 22-44.

Imo, Wolfgang. 2014. Elliptical structures as dialogical resources for the management of understanding. In Susanne Günthner, Wolfgang Imo \& Jörg Bücker (Eds), Grammar and dialogism. Berlin: Mouton. 139-178.

Jackendoff, Ray, 2002. Foundations of Language: Brain, Meaning, Grammar, Evolution. Oxford: Oxford University Press.

Jespersen, Otto, 1924. The Philosophy of Grammar. London: George Allen \& Unwin. Jones, Bob Morris, 1999. The Welsh Answering System. Berlin: Mouton de Gruyter. Koivisto, Aino, To appear. Receipting information as newsworthy vs. responding to redirection. Finnish news particles aijaa and aha(a).Journal of Pragmatics. Koivisto, Aino. To appear. On-line emergence of alternative questions in Finnish with the conjunction/ particle vai 'or'. In: Ritva Laury, Marja Etelämäki \& Elizabeth Couper-Kuhlen (Eds) Linking Clauses and Actions in Social Interaction. Helsinki: Suomalaisen Kirjallisuuden Seura.

Lindström, Jan. Vackert, vackert! Syntaktisk reduplication i svenskan. Studier i nordisk filologi 77. Helsinki: Svenska litteratursällskapet i Finland.

Linell, Per, 2009. Rethinking language, mind, and world dialogically: Interactional and contextual theories of human sense-making. Charlotte, NC: Information Age Publishing. 
Linell, Per \& Christine Mertzlufft, 2014. Evidence for dialogical grammar: reactive constructions in Swedish and German. In: Susanne Günthner, Wolfgang Imo \& Jörg Bücker (Eds), Grammar and dialogism. Berlin: Mouton. 79-108 Merchant, Jason, 2004. Fragments and ellipsis. Linguistics and Philosophy 27: 661738.

Newmeyer, Frederick, 2003. Grammar is grammar and usage is usage. Language 79 (4): 682-707.

Raevaara, Liisa, 1993. Kysyminen toimintana. Kysymys-vastaus vieruspareista arkikeskustelussa. [Questioning as action. On question-answer adjacency pairs in everyday conversation.] Unpublished licenciate’s thesis. Department of Finnish, University of Helsinki.

Raymond, Geoffrey, 2003. Grammar and social organization: Yes/ no interrogatives and the structure of responding. American Sociological Review 68, 939-967. Robinson, Jeffrey D. \& Kevoe-Feldman, Heidi, 2010. Using full repeats to Initiate Repair on Others' Questions. Research on Language and Social Interaction 43 (3), 232-59.

Rossi, Giovanni, 2015. Other-initiated Repair in Italian. Open Linguistics 1: 256-82. Schegloff, Emanuel, 1996. Turn organization: One direction for inquiry into grammar and interaction. In: Elinor Ochs, Emanuel A. Schegloff and Sandra A. Thompson (Eds), Interaction and Grammar. Cambridge: Cambridge University Press. 52-133.

Sadock. Jerrold and Arnold M. Zwicky, 1985. Speech act distinctions in syntax. In: Timothy Shopen (ed.) Language Typology and Syntactic Description, Volume I, Clause Structure. Cambridge: Cambridge University Press. 155-196.

Selting, Margret, 1997. Sogenannte Ellipsen als interaktiv relevante Konstruktionen? Ein neuer Versuch über die Reichweite und Grenzen des Ellipsenbegriffs für die Analyse gesprochener Sprache in Interaktionen. In: Peter Schlobinski (Ed.) Syntax des gesprochenen Deutsch. Opladen: Westdeutscher Verlag. 117-156.

Selting, Margret \& Elizabeth Couper-Kuhlen, 2001. Studies in Interactional Linguistics. Amsterdam: Benjamins.

Sorjonen, Marja-Leena, 2001a. Responding in Conversation. Amsterdam: Benjamins Sorjonen, Marja-Leena, 2001b. Simple answers to polar questions. In Selting, Margret \& Elizabeth Couper-Kuhlen (eds.) Studies in Interactional Linguistics. Amsterdam: Benjamins. 405-430.

Sorjonen, Marja-Leena \& Auli Hakulinen, 2009. Alternative responses to assessments. In Sidnell, Jack (ed.) Conversation Analysis: Comparative Perspectives. Cambridge: Cambridge University Press. 282-302.

Thompson, Sandra A., Barbara Fox \& Elizabeth Couper-Kuhlen, 2015. Grammar in Everyday Talk. Building Responsive Actions. Cambridge: Cambridge University Press. Vatanen, Anna, 2014. Responding in overlap. Agency, epistemicity and social action in conversation. Ph.D. thesis, Department of Finnish, Finno-Ugric and Scandinavian Studies, University of Helsinki.

Voloshinov , Valentin Nikolaevich, 1973 [1929]. Marxism and the philosophy of language. New York: Seminar Press.

Wray, Alison, 2013. Formulaic language. Language Teaching 46 (3) 316-334. 
